\title{
Rate of Returns to Education of Persons with Disabilities in Rural China*
}

\author{
Juan LIAO ${ }^{1}$, Jinbo ZHAO ${ }^{2 *}$ \\ ${ }^{1}$ School of Management, Capital Normal University, Beijing, China \\ ${ }^{2}$ School of Environment, Beijing Normal University, Beijing, China \\ liaojuancnu@gmail.com, henryzjo@bnu.edu.cn
}

\begin{abstract}
The aim of this paper is to estimate the returns to education in the disable people in rural China in the past 20 years. The regression of Mincerian wage equation as the method is used, and the data is based on CHNS data in 1991-2009 survey. The results show that the education level has significant positive linear relationship with the rate of returns to education (RRE). The RRE for the rural disable people is lower than the RRE of the disabled in urban, which are $5.3 \%$ and $7.6 \%$. The RRE of male disabled is higher than the RRE of female. Difference of RRE of disabled people between different regions are significant and East $>$ West $>$ Central is RRE orders in rural regions in China. The results imply that it is necessary to increase supply of special education to improve the education situation of the disabled in rural China and focus on the educational problem in the female disabled.
\end{abstract}

Index Terms - rural; disabled people; returns to education; Mincer regression

\section{Introduction}

Persons with a disability are likely to have limited opportunities to earn income and often have increased medical expenses. According to the 2010 China sixth national census data and Secondary National Disability Sample Survey, the rural-urban distribution of the disabled population in China is 20.71 million in urban and 62.25 million in rural[1]. Unfortunately their status is often careless from public, and lack of relevant research. For persons with disabilities, education can contribute to get a job and integrate into the society. Therefore, education is not only to increase their income, but also plays a very important role in improving the quality of live and realizing themselves. If the rates of returns to education are high, it might be argued that there is an underinvestment in education of the disabled. If the rates are low, expanding human capital intervention as a way to improve employment or earnings may not be indicated [2]. Some existing literature estimate that the returns to education for the disabled and nondisabled, people with different type of disabilities[3][4]. In China, enormous literature exist in the study of the returns to education in recent years, which including urban residents' rate of returns to education [5], rural residents' returns to education [6][7], as well as returns to education of special groups, such as the floating population in urban and rural areas [8], minority [9]. However, more than 80 million disabilities have not yet been studied. The purpose of this paper is to fill this gap by focusing on the role of education and estimate the rate of returns to education in disabled people.

The rest of this paper is organized as follows: section 2 shows the method to estimate the rate of returns to education of individuals with disabilities. Section 3 describes the data set, and followed by a presentation of the empirical results are discussed. Finally, we conclude with findings and recommendations, as well as limitation of our research.

\section{II . Method}

Mincer (1974) equation [10] (also called standard human capital wage equation) is used in this study. Simple Mincer equation only includes two independent variables: schooling years and experience. The equation usually specified as follows:

$$
\ln Y=\beta_{0}+\beta_{1} S+\beta_{2} E X+\beta_{3}(E X)^{2}+\varepsilon
$$

Where S is schooling year, EX is a person's working experience and $\varepsilon$ is an error term. The regression coefficient $\beta_{1}$ represents the returns to education, which indicates how much wage growth rate increases in response to an additional year of schooling and it is called Mincerian rate of return.

Control variables in standard Mincer equation is required, known as the extended Mincer equation, as there are other factors affect individuals' income in reality, such as gender, marital status, household registration of people and their province. Our extended Mincer equation specified as follows.

$$
\begin{aligned}
\ln Y= & \beta_{0}+\beta_{1} S+\beta_{2} E X+\beta_{3}(E X)^{2}+\beta_{4} M A L E \\
& +\beta_{5} M A R R I E D+\beta_{6} H U K O U+\alpha P+\varepsilon
\end{aligned}
$$

Dummy variables 'MALE' represent gender (male $=1$, female $=0$ ); MARRIED is a dummy variable indicating marital status (married $=1$, unmarried $=0$ ); Hukou is individual residence (urban $=1$, rural $=0) ; \mathrm{P}$ is a dummy variable that present province.

\section{III . Data}

\section{A. Data Source}

The data used in this paper is from China Health and

\footnotetext{
* This work is partially supported by Chinese National Social Sciences Fund Grant \#11CJY026 to Juan LIAO.
} 
Nutrition Survey (CHNS). The survey covered the urban and rural areas of China's eastern, central and western regions in nine provinces (Liaoning, Heilongjiang, Shandong, Jiangsu, Henan, Hubei, Hunan, Guangxi, Guizhou). Stratified cluster random sampling method was used in this survey, and the samples are representative for the country. The information about demographic characteristics, socioeconomic status, activities of daily living, body measurements are provided from the data set. Longitudinal data set currently available in 1989, 1991, 1993, 1997, 2000, 2004, 2006, 2009. CHNS data used in this paper has been published after correction by the University of North Carolina Population Center in 2011.

\section{B . Definition of Disability}

Based on Xie's definition of disability [11] and this survey, disability declared via 3 identify questions as follow:

1) Whether respondents' activities of daily living is limited. In their daily activities: walking 200 meters, Climbing a few stairs without stopping, Squatting down, kneeling down, or bending over, Putting on your clothes, Bathing and eating by yourself, and so on. The options to answer these questions: a)no difficulty; b)have some difficulty, but can still do it; c) need help to do it; d)cannot do it at all. People choose $\mathrm{c}$ or $\mathrm{d}$ are defined as disabled.

2) There are some questions whether a person have any of these conditions: blindness in one eye, blindness in both eyes, loss of one arm or use of arm, loss of both arms or use of both arms, loss of one leg or use of one leg, loss of both legs or use of both legs in physical measurements survey. We define these respondents who choose "yes" as disabled. Of course, they are mainly visual and physical disabled persons.

3) "Why are you not working" is one of the questions from this survey. "Disabled" is an option. Individuals who respond this option are included in the scope of persons with disabilities.

\section{Descriptive Statistics}

Table I shows the descriptive statistics of the variables used from 1991 to 2009. Data from 1989 was ignored, as the questions related to the definition of disability were not used in the questionnaire. Background demographic, work status, primary occupation and wages, education and daily activities data set were merged. In accordance with the definition of disability, there were 6966 pooled cross-sectional data selected. The CHNS include investigations in urban site and rural site (not urban and rural household registration, persons with disabilities in rural areas is also included urban and rural household registration), rural areas samples were from the survey of rural site, 4487 pooled cross-section data conform to disabled, contribute $64.41 \%$ of the total disabilities samples. These data included rural household registration and urban household registration $70.19 \%$ and $29.81 \%$. The proportion of the rural population was well matched Secondary National Disability Sample Survey data, and also showed good representative sample.
Income based on personal net revenue after CPI (Consumer Price Index) adjustments in 2009. The regression sample limited to disabled non-students over the age of 16 , and selected a total sample of 3,969 disabilities with 1466 (37.28\%) of the urban disabled people and 2466 (62.72\%) rural disabled people. The descriptive statistics of each variable is shown in Table I. From the comparison of rural and urban samples, the discrepancy of average annual net income from rural and urban disabled people is huge (about 3600 Yuan). In general, disabilities have low education, average 3.3 years in rural and 5.4 years in urban, and both not complete primary education. The proportion of disabilities in rural areas with no schooling were more than $60 \%$ (Table II), indicating that most of them not received formal education, and elementary school or less exceed $80 \%$, only $9.84 \%$ have received junior middle school education, less than $1 \%$ graduated from high school and $0 \%$ received master's and higher education. The data indicate that the educational status of disabilities in rural areas is worrying.

TABLE I Variable Means for Disabled People

\begin{tabular}{|l|c|c|c|c|}
\hline & \multicolumn{2}{|c|}{ Rural } & \multicolumn{2}{c|}{ Urban } \\
\hline Variable name & \#of Obs. & mean & \#of Obs. & mean \\
\hline Income(Yuan) & 2466 & 4397.738 & 1466 & 7989.106 \\
\hline Log income & 2466 & 7.655 & 1466 & 8.517 \\
\hline Education years & 2438 & 3.288 & 1432 & 5.417 \\
\hline Experience & 2435 & 55.637 & 1425 & 55.494 \\
\hline Male & 2466 & 0.461 & 1466 & 0.458 \\
\hline Married & 2433 & 0.980 & 1454 & 0.973 \\
\hline Hukou & 2406 & 0.305 & 1442 & 0.830 \\
\hline
\end{tabular}

TABLE II Educational Status of Disabled People

\begin{tabular}{|l|c|c|}
\hline Educational Level & Number of observations & Percent(\%) \\
\hline Never schooled & 1525 & 62.55 \\
\hline Elementary school & 528 & 21.66 \\
\hline Junior middle school & 240 & 9.84 \\
\hline High school & 76 & 3.12 \\
\hline Professional middle school & 53 & 2.17 \\
\hline Junior college and & 16 & 0.66 \\
\hline college/university & 0 & 0 \\
\hline Graduate or above & 2,438 & 100 \\
\hline Total & & \\
\hline
\end{tabular}




\section{IV . Estimation Results}

Simple Mincer equation was used to calculate returns to education of disabilities in rural areas, the results shown in Table III. $12.4 \%$ was the rate of returns to education without other control variables. With adding the control variables of sex, marital status, household and province (all of the following regression results include dummy variable "province", but the corresponding regression coefficients are not listed in the tables for saving space), the rate of return to education of disabilities in rural areas was $5.3 \%$. This means that for each additional year of education, the income from disabilities will increase $5.3 \%$. Adjusted R-square rises to 0.222 , which is also shows the control variables have a great impact on the returns to education of disabilities. On the other hand, in regression for the urban disabled combine with control variables, the rate of return was $7.6 \%$, higher than the rural disabilities. The overall rate of return to education was $6.4 \%$.

TABLE III Mincerian Regression for All the Disabled, Rural and Urban Persons with Disabilities

\begin{tabular}{|l|l|l|l|l|}
\hline & $(1)$ & $(2)$ & $(3)$ & $(4)$ \\
\hline Variable & Rural & Rural & Urban & All \\
\hline Eduyear & $0.124^{* * *}$ & $0.053^{* * *}$ & $0.076^{* * *}$ & $0.064^{* * *}$ \\
\hline & $(0.008)$ & $(0.009)$ & $(0.007)$ & $(0.006)$ \\
\hline Exp & $0.040^{* * *}$ & $0.026^{*}$ & 0.018 & $0.024^{* *}$ \\
\hline & $(0.013)$ & $(0.014)$ & $(0.015)$ & $(0.011)$ \\
\hline Exp2 & $-0.038^{* * *}$ & $-0.039^{* * *}$ & -0.007 & $-0.028^{* * *}$ \\
\hline & $(0.013)$ & $(0.013)$ & $(0.014)$ & $(0.010)$ \\
\hline Male & & $0.241^{* * *}$ & $0.106^{*}$ & $0.180^{* * *}$ \\
\hline & & $(0.054)$ & $(0.055)$ & $(0.039)$ \\
\hline Married & & $0.373^{* *}$ & 0.244 & $0.321^{* *}$ \\
\hline & & $(0.183)$ & $(0.166)$ & $(0.128)$ \\
\hline Hukou & & $0.919^{* * *}$ & $0.756^{* * *}$ & $0.998^{* * *}$ \\
\hline & & $(0.059)$ & $(0.078)$ & $(0.042)$ \\
\hline Intercept & $6.279^{* * *}$ & $6.786^{* * *}$ & $6.665^{* * *}$ & $6.594 * * *$ \\
\hline & $(0.374)$ & $(0.435)$ & $(0.440)$ & $(0.316)$ \\
\hline Adjusted $\mathrm{R}^{2}$ & 0.119 & 0.222 & 0.270 & 0.296 \\
\hline F statistics & 110.917 & 48.787 & 37.811 & 113.569 \\
\hline$p$-value & {$[0.000]$} & {$[0.000]$} & {$[0.000]$} & {$[0.000]$} \\
\hline $\mathrm{N}$ & 2435 & 2348 & 1393 & 3741 \\
\hline
\end{tabular}

Standard errors in parentheses. $\quad *$ significant at $10 \% ; * *$ significant at $5 \% ; * * *$ significant at $1 \%$.

Education is divided into several levels including no schooling, elementary, junior high and high school or above, no schooling as the reference group. The results (Table IV) showed that, compared to no schooling, returns to education were higher on elementary, junior high, high school and above than higher. The higher educational level, the higher of rate of returns to education they got. School and above got the rate of returns to education $6.82 \%$, but this number was still low compare to the urban.
TABLE IV Regression in Different Educational Level of Disabled People

\begin{tabular}{|l|l|l|l|}
\hline & $(1)$ & $(2)$ & $(3)$ \\
\hline & Rural & Urban & All \\
\hline Elementary school & $0.170^{* *}$ & $0.252^{* * *}$ & $0.224^{* * *}$ \\
\hline & $(0.072)$ & $(0.076)$ & $(0.053)$ \\
\hline Junior middle school & $0.331^{* * *}$ & $0.580^{* * *}$ & $0.449^{* * *}$ \\
\hline & $(0.099)$ & $(0.090)$ & $(0.070)$ \\
\hline High school or above & $0.682^{* * *}$ & $0.848^{* * *}$ & $0.733^{* * *}$ \\
\hline & $(0.125)$ & $(0.087)$ & $(0.075)$ \\
\hline Exp & $0.027^{*}$ & 0.021 & $0.026^{* *}$ \\
\hline & $(0.014)$ & $(0.015)$ & $(0.011)$ \\
\hline Exp2 & $-0.043^{* * *}$ & -0.012 & $-0.032^{* * *}$ \\
\hline & $(0.013)$ & $(0.014)$ & $(0.010)$ \\
\hline Male & $0.281^{* * *}$ & $0.155^{* * *}$ & $0.223^{* * *}$ \\
\hline & $(0.053)$ & $(0.054)$ & $(0.039)$ \\
\hline Married & $0.375^{* *}$ & 0.255 & $0.325^{* *}$ \\
\hline & $(0.183)$ & $(0.167)$ & $(0.129)$ \\
\hline Hukou & $0.923^{* * *}$ & $0.804^{* * *}$ & $1.021^{* * *}$ \\
\hline & $(0.059)$ & $(0.077)$ & $(0.042)$ \\
\hline Intercept & $6.858^{* * *}$ & $6.746^{* * *}$ & $6.684^{* * *}$ \\
\hline & $(0.434)$ & $(0.442)$ & $(0.316)$ \\
\hline Adjusted $\mathrm{R}^{2}$ & 0.221 & 0.265 & 0.294 \\
\hline F statistics & 42.648 & 32.434 & 98.535 \\
\hline$p$-value & {$[0.000]$} & {$[0.000]$} & {$[0.000]$} \\
\hline $\mathrm{N}$ & 2348 & 1393 & 3741 \\
\hline
\end{tabular}

Standard errors in parentheses. * significant at $10 \%$;* significant at $5 \%$; *** significant at $1 \%$.

No matter using years of education or educational level as the key variables return to education, OLS regression shows that the coefficients of gender are significant. It means that male has higher rate of return than female disabilities. The return to education of disabled men was $6.9 \%$ and $4.5 \%$ for women by gender (Table V). 2.4 percent higher in men than women. Gender difference in returns to education in the disabled persons is proved to be significant.

TABLE V Regression by Gender in Rural Disabled People

\begin{tabular}{|l|l|l|l|}
\hline & $(1)$ & $(2)$ & $(3)$ \\
\hline & All & Male & Female \\
\hline Eduyear & $0.068^{* * *}$ & $0.069^{* * *}$ & $0.045^{* * *}$ \\
\hline & $(0.009)$ & $(0.012)$ & $(0.014)$ \\
\hline Exp & $0.028^{* *}$ & 0.003 & $0.041^{*}$ \\
\hline & $(0.014)$ & $(0.019)$ & $(0.021)$ \\
\hline Exp2 & $-0.039^{* * *}$ & -0.009 & $-0.061^{* * *}$ \\
\hline & $(0.013)$ & $(0.018)$ & $(0.019)$ \\
\hline Male & $0.336^{*}$ & $0.433^{*}$ & 0.298 \\
\hline & $(0.184)$ & $(0.234)$ & $(0.286)$ \\
\hline Married & $0.913^{* * *}$ & $0.886^{* * *}$ & $0.925^{* * *}$ \\
\hline & $(0.059)$ & $(0.081)$ & $(0.086)$ \\
\hline Hukou & $6.735^{* * *}$ & $7.353^{* * *}$ & $6.508^{* * *}$ \\
\hline & $(0.437)$ & $(0.573)$ & $(0.664)$ \\
\hline Adjusted $\mathrm{R}^{2}$ & 0.216 & 0.239 & 0.180 \\
\hline F statistics & 50.609 & 26.940 & 22.490 \\
\hline$p$-value & {$[0.000]$} & {$[0.000]$} & {$[0.000]$} \\
\hline $\mathrm{N}$ & 2348 & 1075 & 1273 \\
\hline
\end{tabular}

Standard errors in parentheses. * significant at $10 \%$; $*$ significant at $5 \%$; *** significant at $1 \%$. 
Regional development is unbalanced in China, so the development of education has big difference between the regions. Mincerian regression based on the eastern, central and western rural areas shows in Table VI. The rate of returns to education in western, central and eastern is $4.9 \%, 3.8 \%$ and $6.7 \%$ respectively. The data illustrates that region is an important factor that affects the rate of returns to education. In all regressions, the rate of returns to education in urban is higher than rural. This also shows that the returns to education with disabilities urban-rural difference are significant. Marital status is the same effect on the rate of returns to education as previous findings found, which is higher in married than unmarried, but in all regressions of returns to education, the coefficient did not show a consistent significance in our research.

TABLE VI Regression Coefficient by Regions in Rural Disabled People

\begin{tabular}{|l|l|l|l|}
\hline & $(1)$ & $(2)$ & $(3)$ \\
\hline & West & Central & East \\
\hline & $0.049 * * *$ & $0.038^{* *}$ & $0.067^{* * *}$ \\
\hline Exp & $(0.016)$ & $(0.016)$ & $(0.015)$ \\
\hline & $0.059 * *$ & -0.005 & 0.030 \\
\hline Exp2 & $(0.027)$ & $(0.021)$ & $(0.028)$ \\
\hline & $-0.077 * * *$ & -0.010 & -0.040 \\
\hline Male & $(0.024)$ & $(0.019)$ & $(0.025)$ \\
\hline & -0.033 & $0.360 * * *$ & $0.438^{* * *}$ \\
\hline Married & $(0.098)$ & $(0.088)$ & $(0.093)$ \\
\hline & $0.691 *$ & 0.262 & 0.245 \\
\hline Hukou & $(0.362)$ & $(0.282)$ & $(0.312)$ \\
\hline & $0.884 * * *$ & $0.725 * * *$ & $1.194 * * *$ \\
\hline Intercept & $(0.107)$ & $(0.097)$ & $(0.101)$ \\
\hline & $5.632 * * *$ & $7.454 * * *$ & $6.390 * * *$ \\
\hline Adjusted $\mathrm{R}^{2}$ & $(0.811)$ & $(0.612)$ & $(0.811)$ \\
\hline F statistics & 0.166 & 0.150 & 0.346 \\
\hline$p$-value & 27.214 & 27.421 & 59.274 \\
\hline $\mathrm{N}$ & {$[0.000]$} & {$[0.000]$} & {$[0.000]$} \\
\hline
\end{tabular}

Standard errors in parentheses. * significant at $10 \%$; ** significant at $5 \%$; *** significant at $1 \%$.

\section{Conclusions}

The following conclusions are made from this study: First, compared with the urban, people with disabilities in rural areas have less return to education at $5.3 \%, 2.3$ percentage points lower than urban. Second, rural and urban show a trend that the higher rate of returns to education towards to increasing level of education. Thirdly, in rural disabled men has better advantage than disabled women at return to education. Fourth, the return to education of the rural disabled between regions is significantly different, its order is: East $>$ West $>$ Central. In rural areas, education status and returns to education of persons with disabilities show a "double low" phenomenon.

Education of the disabled and their income is closely relative. In rural areas, average years of education of disabled people are very low, which has negative effect on their income increases. Persons with disabilities always requires special needs, their spending in medicinal, health care, life are higher compared to non-disabled. If people with disabilities fell into a circle of "poor education - low income - poverty - disease", that will increase the influence of disability on themselves and their family. Therefore improvement in the overall educational status of the disabled in rural areas to increase their income is fundamental measures to alleviate the disadvantageous consequences caused by disabilities. At this stage, the most important is to increase effective supply of special education in rural regions, such as establishment of more schools for the handicapped, training of special education teachers and encourage persons with disabilities into the school. The policy makers should pay more attention to the more vulnerable groups in the disability groups. The disabled female in rural areas is the weakest of the weak group, and they need more help from public and government.

Current study shows that returns to education of persons with disabilities has been ignored for many years, few Chinese scholars involved in this research area. Although a multi-level analysis of the returns to education of persons with disabilities in rural areas was presented in this paper, but the analysis is not far enough to understand educational status of the disabled. Firstly, the definition of disability according to the CHNS data of features, it cannot contain all type of persons with disabilities, such as mental, intellectual, speech and hearing disabilities. Secondly, due to lack of comprehensive region information, the conclusions of returns to education for the eastern, central and western may have its limitations. Finally, although the CHNS data covers 20 years from 1989 to 2009, there is still limit data from each wave to display the trend of returns to education. Therefore, more data required on the survey of disabilities in public to support researchers for further studies. We also would like to call on scholars engaged in the study of persons with disabilities to promote the development of the disabled.

\section{References}

[1] http://www.cdpf.org.cn/sytj/content/200711/21/content_30316035_3.htm

[2] K. Hollenbeck, J. Kimmel, "Differences in the Returns to Education for Males by Disability Status and Age of Disability Onset," Southern Economic Journal, vol. 74, no. 3, pp. 707-724, January 2008.

[3] K. Hollenbeck, J. Kimmel, "The Returns to Education and Basic Skills Training for Individuals with Poor Health or Disability," Upjohn Institute Staff Working Paper No. 01-72,2001.

[4] K. Lamichhane, Y. Sawada, "Disability and Returns to Education in a Developing Country," CIRJE Discussion Paper No.CIRJE-F-645,2009.

[5] S. Li, S. Ding, "Long-term Change in Private Returns to Education in Urban China," Social Sciences in China, no.6, pp. 58-72, 2003.

[6] F.Y. Hou, "The Study on Rates of Investment Return to Human Capital in China Rural Areas," Economic Research Journal, no. 12, pp. 75-84, 2004.

[7] L.T. Zhao, "Rising Returns to Education in Rural China," Social Sciences in China, no.3, pp. 98-109, 2006.

[8] Y. Ma, et al., "Education Return to Migrants: An Analysis Based on a Three-province Survey in China," Population Journal, no.2, pp.64-73, 2012.

[9] D.H. Meng, L.F. Su and D.S. Lai, "An Empirical Study on the Returns to Education of the Ethnic Minorities in Chinese Cities and Towns in the Economic Transition Period," Ethno-National Studies, no.1,pp.2534, 2012.

[10] J. Mincer, Education, Experience and Earnings. New York: Columbia University Press, 1974.

[11] E. Xie, "Disability and Labor Market," Management World, no.4, pp.37-45, 2011. 